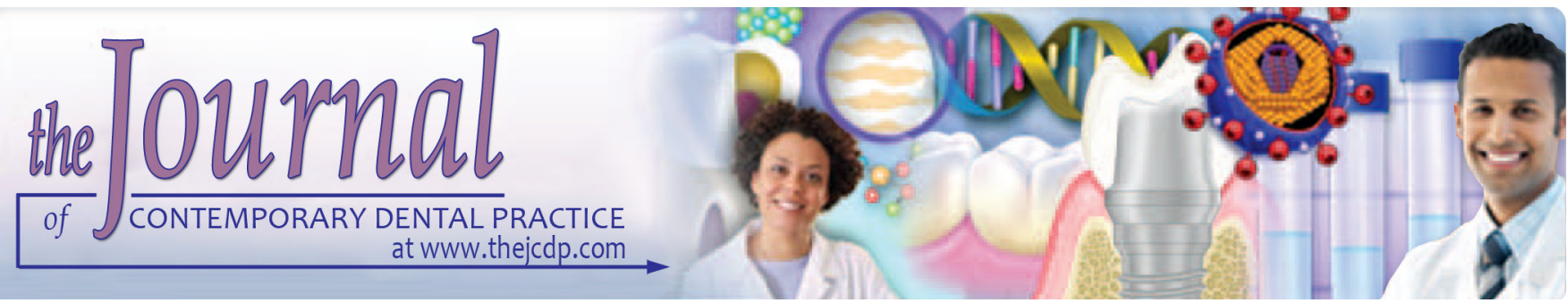

\title{
Assessment of Lingual Concavities in Submandibular Fossa Region in Patients requiring Dental Implants- A Cone Beam Computed Tomography Study
}

\author{
${ }^{1}$ Bhoopendera S Rajput, ${ }^{2}$ Sandeep Mehta, ${ }^{3}$ Anuj S Parihar, ${ }^{4}$ Tarun Vyas, ${ }^{5}$ Prabhjot Kaur, ${ }^{6}$ Shivakshi Chansoria
}

\begin{abstract}
Aim: The present study was aimed at assessing the lingual concavities in the submandibular fossa region in patients requiring dental implants with the help of cone beam computed tomography (CBCT).
\end{abstract}

Materials and methods: The present study included 140 patients who visited the department with the missing mandibular posterior teeth. CBCT images were obtained using planmeca machine. Cross sections of $1 \mathrm{~mm}$ of submandibular fossa in the region of 1 st and 2 nd molar were studied and Type I to III lingual concavities were analyzed by a radiologist.

Results: Type I lingual concavity $(<2 \mathrm{~mm})$ was seen in $23 \%$, type II $(2-3 \mathrm{~mm})$ in $62 \%$ and Type III (>3 mm) in $15 \%$ of patients. The difference was significant $(p<0.05)$. Males had slightly higher mean \pm S.D value at 1 st molar $(2.6 \mathrm{~mm} \pm 0.94)$ and 2 nd molar $(2.8 \mathrm{~mm} \pm 0.90)$ on the left side and $(2.7 \mathrm{~mm} \pm 0.92)$ at 1 st molar and $(2.9 \mathrm{~mm} \pm 0.93)$ at $2 \mathrm{nd}$ molar on the right side. The difference was nonsignificant $(p>0.05)$. Females had mean $\pm S$. $D$ value at 1 st molar $(2.3 \mathrm{~mm} \pm 0.90)$ and $(2.5 \mathrm{~mm} \pm 0.92)$ at $2 \mathrm{nd}$ molar on the left side and $(2.4 \mathrm{~mm} \pm 0.91)$ at $1 \mathrm{st}$ molar and $(2.8 \mathrm{~mm} \pm 0.93)$ at 2nd molar. The difference was nonsignificant $(p>0.05$. The difference between both genders was statistically nonsignificant $(p>0.05)$.

${ }^{1}$ Department of Oral and Maxillofacial Surgery, RR Dental College, Udaipur, Rajasthan, India

${ }^{2}$ Department of Periodontology, JCD Dental College, Sirsa, Haryana, India

${ }^{3}$ Department of Periodontology, RKDF Dental College and Research Centre, Bhopal, Madhya Pradesh, India

${ }^{4}$ Department of oral medicine and radiology, R.R. Dental college and hospital, Udaipur, Rajasthan, India.

${ }^{5}$ Department of Oral Pathology and Microbiology, Desh Bhagat Dental College and Hospital, Mandi Gobindgarh, Punjab, India

${ }^{6}$ Index Institute of Dental Sciences, Indore, Madhya Pradesh, India

Corresponding Author: Bhoopendera S Rajput, Deparment of Oral and Maxillofacial Surgery, RR Dental College, Udaipur, Rajasthan, India, Phone: +919501544877, e-mail: drbhoopnderar@gmail.com
Conclusion: Type I bone is the best for placing an implant. The chances of complications are more in type II and III bone. CBCT provides necessary information before planning implant in the edentulous area.

Clinical significance: Cone beam computed tomography (CBCT) is the best radiographic aid which is effective in delineating different types of bone in the mandibular posterior region.

Keywords: Cone beam computed tomography (CBCT), Implant, Submandibular fossa.

How to cite this article: RajputBS, Mehta S, Parihar AS, Vyas T, Kaur P, Chansoria S. Assessment of Lingual Concavities in Submandibular Fossa Region in Patients requiring Dental ImplantsA Cone Beam Computed Tomography Study. J Contemp Dent Pract 2018;19(11):1329-1333.

Source of support: Nil

Conflict of interest: None

\section{INTRODUCTION}

Dental implants have revolutionized the present scenario of dentistry. With the advancement in the field of dental implants, the replacement of missing teeth is now not considered as a complicated process. Endosseous implants are widely used nowadays and have become a treatment of choice in edentulous areas. The success of dental implants is highly appreciable, and long-term survival is needed for the betterment of the patients. ${ }^{1}$

There are certain challenges during the placement of dental implants. Anatomical structures such as the floor of the nasal cavity, floor of the maxillary sinus, mental foramen, inferior alveolar nerve canal, submandibular gland fossa, etc. are considered to be the area which warrants careful assessment before surgical procedures. The presence of anatomical limitations requires analysis to ensure the best outcome of the treatment. ${ }^{2}$

The placement of the dental implant in the mandibular posterior region demands careful analysis of anatomical 
landmarks such as submandibular gland fossa, inferior alveolar canal and mental foramen to minimize the complications. Paresthesia of lower lip and chin are among few complaints. This may result from damage to the mental nerve or inferior alveolar nerve during surgical procedures. The removal of impacted third molar sometimes leads to injury to the neurovascular bundle. Severe hemorrhage in the region may be seen. In the case of the edentulous mandible, the chances of iatrogenic complications are more. Therefore, a thorough determination of all parameters such as bone height, width, the presence of undercuts, concavities, bone depth, etc. is needed. ${ }^{3}$

Assessment of the dental implant site with the help of intraoral radiographs such as periapical radiographs and extraoral radiographs such as panoramic views provides insufficient information. Other methods like intraoral palpation of the area, dental casts are lacking useful details of the anatomical variation and bone morphology. Thus, there is a need for a reliable method which is universally accepted. CBCT being three dimensional overcome all limitations of two-dimensional (2D) imaging modalities. ${ }^{4}$ Considering this, the present study aimed at assessment of depth of submandibular gland fossa with CBCT.

\section{MATERIALS AND METHODS}

This retrospective study was performed in the Department of Prosthodontics. It included 140 patients requiring dental implants in the posterior mandibular region. All were informed regarding the study, and written consent was obtained. Ethical clearance was obtained before starting the study. Patients with missing mandibular posterior teeth, sufficient bone height and edentulism not more than 2 years were included in the study. Patients with insufficient bone height, any bone surgery performed in the mandibular posterior region and poor quality CBCT images were excluded.

Patients were subjected to CBCT taken with planmeca machine following standardized parameters (40 mA, 120 $\mathrm{kVp}$ and 40 seconds). The $8 \times 11 \mathrm{~cm}$ field of view (FOV) was utilized. Axial, coronal and sagittal sections were obtained. The multiplanar reformation was done, and images of $1 \mathrm{~mm}$ were selected in the mandibular posterior region (distal to mental foramen). Coronal sections in the region of first and second molar where lingual concavity appears to be maximum were selected on images. A line was drawn joining the most prominent superior and inferior points on the lingual concavity and was marked as A. Other line was drawn from deepest point of the fossa at right angle to the line A and was marked as B. The length of line B was measured in first and second molar region in all sections and sections in which length is maximum were considered (Fig. 1). This represented the depth of submandibular gland fossa. Special NNT software was used for the measurements.

Three variations, type I with $<2 \mathrm{~mm}$ of lingual concavity (Fig. 2), type II with $2 \mathrm{~mm}$ to $3 \mathrm{~mm}$ of lingual concavity (Fig. 3) and type III with $>3 \mathrm{~mm}$ of concavity (Fig. 4) was considered. ${ }^{4}$ All measurements were performed by single radiologist to prevent inter radiologist errors. Once measurements were completed, the same procedure was repeated after 2 weeks, and the average of both readings was used as the final reading. Results thus obtained were subjected to statistical analysis using Statistical Package for the Social Sciences (SPSS) software 18.0. A p-value $<0.05$ was considered significant.

\section{RESULTS}

Out of 140 patients, males were 60 and females were 80 . The difference was non- significant $(p-0.21)$. The mean age of males was 47.2 years and in females was 44.5 years $(p>0.05)$

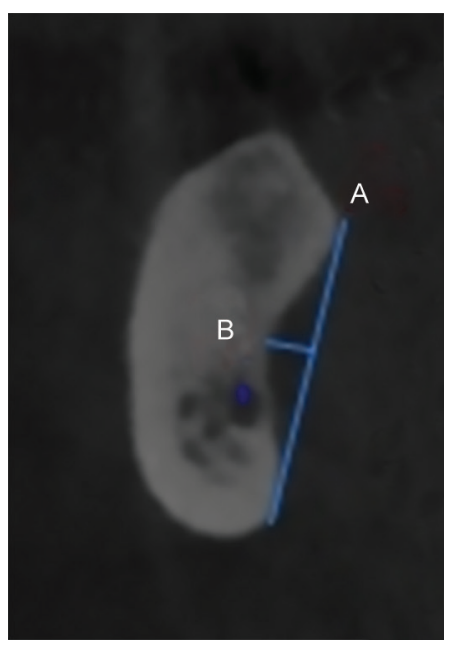

Fig. 1: Cross section showing point $A$ and point $B$

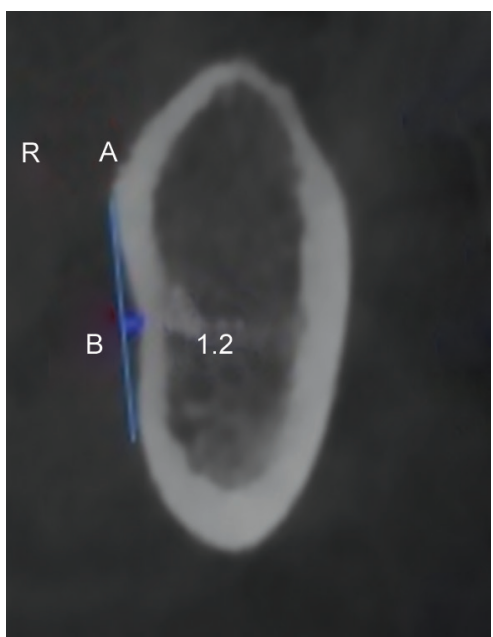

Fig. 2: Cross section showing type I bone 


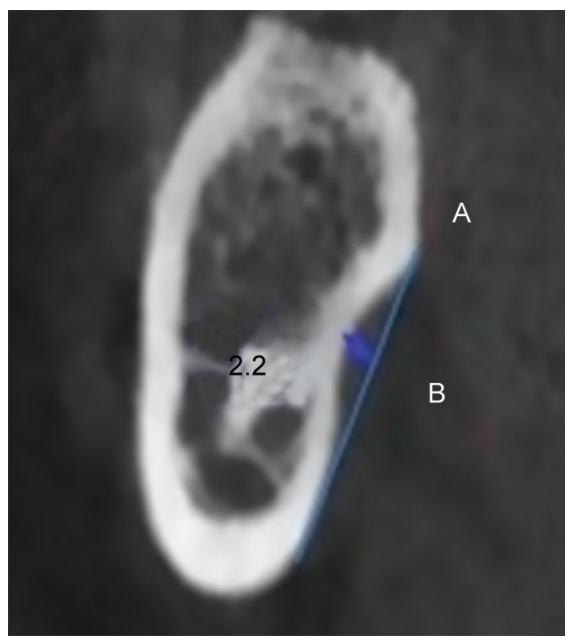

Fig. 3: Cross section showing type II bone

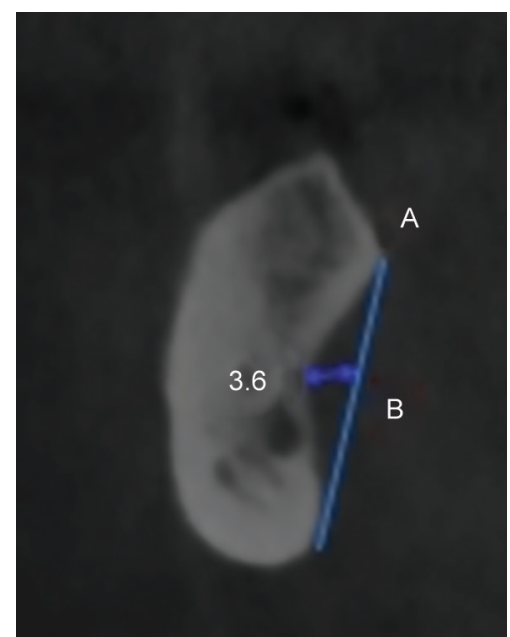

Fig. 4: Cross section showing type III bone

Table 1: Distribution of patients

\begin{tabular}{llll}
\multicolumn{3}{c}{ Total 140} \\
\hline Gender & Males & Females & $p$-value \\
\hline Number & 60 & 80 & 0.21 \\
Mean age (years) & 47.2 & 44.5 & \\
\hline
\end{tabular}

Table 2: Measurement of submandibular gland fossa in males on left and right side

\begin{tabular}{lllllll}
\hline & \multicolumn{2}{c}{ Left side } & & \multicolumn{2}{c}{ Right side } & \\
\cline { 2 - 3 } Measurement & 1st molar & $2 n d$ molar & & 1st molar & 2nd molar & $p$-value \\
\hline Mean $\pm \mathrm{SD}$ & $2.6 \mathrm{~mm} \pm 0.94$ & $2.8 \mathrm{~mm} \pm 0.90$ & & $2.7 \mathrm{~mm} \pm 0.92$ & $2.9 \mathrm{~mm} \pm 0.93$ & 0.5 \\
\hline
\end{tabular}

Table 3: Measurement of submandibular gland fossa in females on left and right side

\begin{tabular}{lllllll}
\hline & \multicolumn{2}{c}{ Left side } & & \multicolumn{2}{c}{ Right side } & \\
\cline { 2 - 3 } Measurement & 1st molar & 2nd molar & & 1st molar & 2nd molar & $p$-value \\
\hline Mean $\pm \mathrm{SD}$ & $2.3 \mathrm{~mm} \pm 0.90$ & $2.5 \mathrm{~mm} \pm 0.92$ & & $2.4 \mathrm{~mm} \pm 0.91$ & $2.8 \mathrm{~mm} \pm 0.93$ & 0.1 \\
\hline
\end{tabular}

(Table 1). The mean \pm SD value of submandibular gland fossa in males on the left side at 1 st molar was $2.6 \mathrm{~mm} \pm 0.94$ and at 2 nd molar was $2.8 \mathrm{~mm} \pm 0.90$ whereas on the right side the value was slightly higher, i.e., $2.7 \mathrm{~mm} \pm 0.92$ at 1 st molar and $2.9 \mathrm{~mm} \pm 0.93$ at 2 nd molar. The difference of values at 1 st and 2 nd molar, on both sides, was nonsignificant $(p>0.05)$ (Table 2). The mean \pm SD value of submandibular gland fossa in females on the left side at 1st molar was $2.3 \mathrm{~mm} \pm 0.90$ and at $2 \mathrm{nd}$ molar was $2.5 \mathrm{~mm} \pm 0.92$ and on the right side, $2.4 \mathrm{~mm} \pm 0.91$ at 1 st molar and $2.8 \mathrm{~mm} \pm 0.93$ at 2 nd molar. The difference of values at 1 st and 2 nd molar, on both sides, was nonsignificant ( $p>0.05)$ (Table 3). Twentythree percent of patients had $<2 \mathrm{~mm}$ of lingual concavity (type 1), 62\% exhibited 2 to $3 \mathrm{~mm}$ of lingual concavity (type 2 ) and $15 \%$ showed $>3 \mathrm{~mm}$ of lingual concavity (type 3 ). The difference was significant $(\mathrm{p}<0.05)$ (Graph 1).

\section{DISCUSSION}

Dentists may encounter several difficulties in the placement of dental implants in maxilla and mandible.

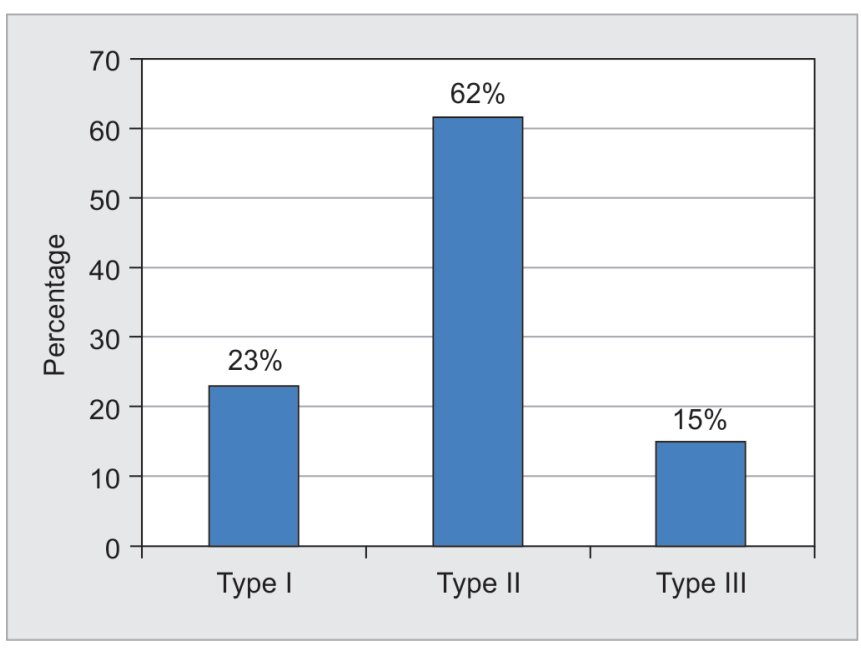

Graph 1: Different types of lingual concavities

The presence of undercuts in jaws and concavities are biggest drawbacks. Careful presurgical assessment of implant site is recommended to avoid failure of the treatment. Various radiographs were being used. Earlier intraoral radiographs such as periapical radiographs, 
panoramic radiographs were providing the details. There was a limitation in their use. All above said radiographs were depicting two-dimensional information. Even American Academy of Oral and Maxillofacial Radiology (AAOMR) suggested the use of cross-sectional imaging to evaluate any potential implant site. ${ }^{5}$ The availability of CBCT has revolutionized the dentistry as the missing third dimension had been boon to the implant dentistry.

In our present study, we evaluated submandibular gland fossa in patients demanding dental implants in the posterior mandibular region with the help of CBCT. Chan et al. ${ }^{6}$ in their study analyzed the lingual concavities using $\mathrm{CBCT}$ and classified ridges into undercuts, convex and parallel. Another study by Chau et al. ${ }^{7}$ compared CT, CBCT and spiral CT in presurgical implant insertion and found CBCT better than other modalities on the basis that it provides sufficient diagnostic information with less patient exposure.

In the present study, depth of submandibular fossa was measured at 1st molar and second molar region on both sides. We found that maximum value was obtained on the second molar as compared to the first molar and right side exhibited slightly more depth, though the difference was nonsignificant $(p>0.05)$. Males had more value as compared to females.

We found that type I lingual concavity was seen in $23 \%$, type II in $62 \%$ and type III in $15 \%$ of cases. Type II exhibited a significantly higher percentage compared to other types. Similar results were obtained by Parnia et al. ${ }^{8}$ They evaluated submandibular fossa volume from multislice CT scans of patients requiring endosseous implants. Lingual concavity with depth $>2 \mathrm{~mm}$ was seen in $80 \%$ of the patients.

We found that mean \pm SD depth was $2.82 \mathrm{~mm} \pm 0.92$ at second molar in males and $2.61 \mathrm{~mm} \pm 0.93$ in females. Parnia $^{8}$ in Iranian population found $2.6 \pm 0.85 \mathrm{~mm}$ depth. Nickenig et al. ${ }^{9}$ utilized cross sections of CBCT in determining concavities in the mandible and found $56 \%$ of undercut type of mandible in the first molar region.

Watnable ${ }^{10}$ conducted a study on mandible size and morphology determined with CT on a premise of dental implant operation and found lingual concavities in 37\% of the study population. They observed that maximum concavities were present in the first molar region. The most common complication while placing a dental implant in the mandibular posterior region is an injury to mental and inferior alveolar nerve. Careful analysis may prevent any damage. A study by Forum et al. ${ }^{11}$ has advised assessment of dental implant site using computer tomography to avoid injury to the inferior alveolar nerve (IAN).

Hofschneider $^{12}$ analyzed bleeding complications in the interforaminal region during implant insertion and suggested that the angulation and proper selection of dental implant are mandatory to avoid hemorrhage in the region. A recent study by Lin et al. ${ }^{13}$ in the year 2014 evaluated risk associated with inferior alveolar nerve injury for immediate implant placement in the posterior mandible and concluded that mandibular lingual concavities are predisposing factors leading to lingual cortical plate perforation.

Cone beam computed tomography (CBCT) was used for the present study. The advantages of CBCT helped in measuring the depth of the submandibular gland fossa effectively as compared to panoramic radiographs. The $2 \mathrm{D}$ nature of panoramic radiographs is lacking in providing useful information. There are image distortion and magnification of the resultant image. Moreover, the sagittal, coronal and axial sections were utilized, and all the planes proved to be beneficial. The 3D nature of CBCT is highly efficient in assessing the submandibular gland fossa with lesser patient dose as compared to CT. The quality of CBCT is not compromised. ${ }^{14}$

Givol et al. ${ }^{15}$ in their study suggested that improper implant placement may result in life-threatening complications. The awareness of anatomical structures and the proper planning of the treatment are probably the best way to avoid surgical complications. The knowledge of lingual concavities in mandible helps in planning dental implants. The selection of a dental implant, its shape and size may be better understood. The point of entry of drill can be planned accordingly. Incorrect drill insertion results into perforation and hence severe bleeding in the region. The chances of lingual perforation are more if types II and III bone is present. The better results are seen when implants are inserted in type I bone. $^{16}$

Thus, radiographic examination of the implant site becomes mandatory to avoid iatrogenic complications. $\mathrm{CBCT}$ is very capable as cross-sectional views enable a better understanding of bone quality, morphology and the anatomy of submandibular gland fossa. Uchida et al. ${ }^{17}$ in their study of measurement of the depth and location of the sublingual fossa and found that the greatest depth is present in the premolar region.

The limitation of the study is that only those patients who required dental implants in the mandibular posterior region were considered. Patients with missing maxillary and mandibular anterior teeth were not considered.

\section{CONCLUSION}

There are certain challenges while planning dental implants in the maxilla and mandible. The presence of inferior alveolar canal, mental foramen, submandibular 
gland fossa and lingual concavities are among them. Type I bone offers better implant survival rate as compared to type II and III. The chances of hemorrhage are less in type I bone. CBCT is very effective in providing useful details as compared to panoramic and other radiographs. The presurgical analysis of implant site is mandatory to avoid complications such as hemorrhage resulting from injury to inferior alveolar nerve or mental nerve. Thus the precise assessment of bone quality and morphology guides dentist to finalize treatment plan. CBCT being three dimensional offers fine details and less patient exposure.

\section{REFERENCES}

1. Gahleitner A, Hofschneider U, Tepper G, Pretterklieber M, Schick S, Zauza K, et al. Lingual vascular canals of the mandible: evaluation with dental CT. Radiology. 2001; 220:186-189.

2. Isaacson TJ. Sublingual hematoma formation during immediate placement of mandibular endosseous implants. J Am Dent Assoc. 2004; 135:168-172.

3. Kalpidis CD, Konstantinidis AB. Critical hemorrhage in the floor of the mouth during implant placement in the first mandibular premolar position: a case report. Implant Dent. $2005 ; 14: 117-124$.

4. Jung T. Study of fovea submandibularis during pre-implant diagnostics. J Friadent Implant 2004; 1:34-37.

5. American Academy of Implant Dentistry. Glossary of implant terms. J Oral Implantol. 1986; 12:284-294.

6. Chen, L.C., Lundgren, T., Hallstrom, H. \& Cherel, F. Comparison of different methods of assessing alveolar ridge dimensions prior to dental implant placement. Journal of Periodontology. 2008; 79: 401-405.

7. Chau ACM, Fung K. Comparison of radiation dose for implant imaging using conventional spiral tomography, computed tomography, and cone-beam computed tomography. Oral Surg Oral Med Oral Pathol Oral Radiol Endod 2009; 107:559-565.
8. Parnia F, Fard EM, Mahboub F, Hafezeqoran A, Gavgani FE. Tomographic volume evaluation of submandibular fossa in patients requiring dental implants. Oral Surg Oral Med Oral Pathol Oral Radiol Endod. 2010; 109:32-36.

9. Nickenig HJ, Wichmann M, Eitner S, Zöller JE, Kreppel M. Lingual concavities in the mandible: a morphological study using cross sectional analysis determined by CBCT. J Craniomaxillofac Surg. 2015; 43:254-259.

10. Watanabe H, Mohammad Abdul M, Kurabayashi T, Aoki H. Mandible size and morphology determined with CT on a premise of dental implant operation. Surg Radiol Anat. 2010; 32:343-349.

11. Froum S, Casanova L, Byrne S, Cho SC. Risk assessment before extraction for immediate implant placement in the posterior mandible: a computerized tomographic scan study. J Periodontol. 2011; 82:395-402.

12. Hofschneider U, Tepper G, Gahleitner A, Ulm C. Assessment of the blood supply to the mental region for reduction of bleeding complications during implant surgery in the interformainal region. Inj J Oral Maxillofac Implants. 1999; 14:379-383.

13. Lin MH, Mau LP, Cochran DL, Shieh YS, Huang PH, Huang RY. Risk assessment of inferior alveolar nerve injury for immediate implant placement in the posterior mandible: a virtual implant placement study. J Dent. 2014;

14. Lofthag-Hansen S, Grondahl K, Ekestubbe A. Cone-beam CT for preoperative implant planning in the posterior mandible: visibility of anatomic landmarks. Clin Implant Dent Relat Res. 2009; 11:246-255.

15. Givol N, Chaushu G, Halamish-Shani T, Taicher S. Emergency tracheostomy following life-threatening hemorrhage in the floor of the mouth during immediate implant placement in the mandibular canine region. J Periodontol. 2000;7 1: 1893-1895.

16. Cantekin K, Sekerci AE, Miloglu O, Buyuk SK. Identification of the mandibular landmarks in a pediatric population. Med Oral Patol Oral Cir Bucal. 2014; 19:136-141.

17. Uchida Y, Goto M, Danjo A, Yamashita Y, Kuraoka A. Anatomic measurement of the depth and location of the sublingual fossa. Int J Oral Maxillofac Surg 2012; 41:1571-1576. 